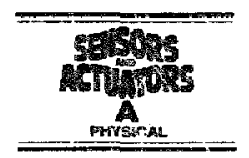

\title{
An IC-compatible polyimide pressure sensor with capacitive readout
}

\author{
M. Pedersen *. M.G.H. Meijerink. W. Olthuis, P. Bergveld

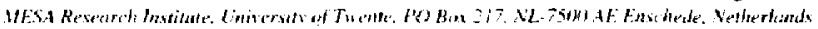

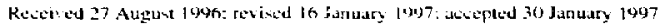

\begin{abstract}
A cupacitive differential presure sensor has hesh developed. The preacens uned tor the fibriction of the sensor is IC-compatible, meaning that the device potentially can be integrated on one thip with a suitable vignal-conditioning eircut. A sensor for a differential pressure of

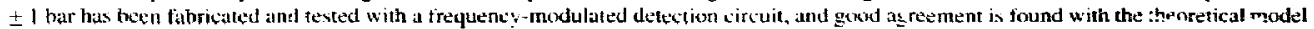
of the sensor. A nominal sensitiv ity $3 \mathrm{C} / \mathrm{C}$ of $17 \mathrm{r}$; has been measured for a positive differential pressure of 1 har. The resolution $\mathrm{Cf}$ sire complete detection system is 2.5 mbar $(250 \mathrm{~Pa}$ ). a) 1097 Else' ier Science S.A.
\end{abstract}

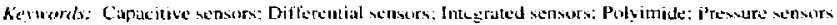

\section{Introduction}

The development of integrated tapacitive pressure sensors fabricated by means ot micromechanical processes $\mid[-8 \mid$ hats until now been hampered by the complexity of the structures and the fabuication process. Il is well known that the capacitive detection principle is supreme, concerniog sensitivity and power consumption. However. since the electrical cupacitances are normally very snall. the electrical connections (o) the sensor are very sensitive to parasitics and noise. There fore, it is desirable to make the connections as short and welldetined as possible. The ulcimate solution to this problem is to integrate the sensor directly on the same chip as the signalconditioning circuit, whereby the physical distance between the two elements is both short and well defined. The basic problem of integrating it sensor and an jntegrated circuit is that the fabrication processes have to be compatible. Since the fabrication processes used for electronic cifcuits are very complex and sensitive to even small changes or modifications. the introduction of a sensor process has to beconsidered carefully. Previousiy, many suggestions how to approach this problem have been given.

One of the first integrated capacitive pressure sensors was presentect by Sinder et al. [1]. This sensor was fabricated by honding a glass plate, contioning the counter electrode, to the silicon water, in which a diaphragm was etched. This approach liad the foundalion for many later developments $|2-6|$ of capacitive pressure sensors with different integrated

\footnotetext{
* Coresponding author. Tel: + +315.74.892722. Fax: + $3153+592287$ (1)24-42+7/97/\$17,00 61097 Elsevier Science S. A. All rights reserved PIIS0924.42476 J7 I01507-6
}

signal-conditioning circuits. Lately, single-substrate sentsors made by surtace mic romachining have been proposed $[7,8]$. whereby the need to bond the silicon substrate to another substrate has been eliminaled. This must be considered as an improvement. since the bonding processes until now have been diflicul: to control. and therefore have had a relatively low y ield. Since this process is normally one of the last in the complete process line, it yield as close to $100 \%$ as possible is absolutely essential. The integrated single-chip pressure sensots of Kung and Lee $|7|$ and Dudaicevs et al. [8] both had a polysilicon membrine. which was formed by introducing extra process steps in a standard CMOS process. Unfortunately, this approach mily have an influence on the characteristics of the electronic circuitry, which has to be determined. In this paper we report on a fabrication process for a single-chip capacitive pressure ser-ior, which can be carried out as a poit-process after the complet or of the electronic circuit at a relatively low process temperature. No modifications of the delicate IC process are required. because the sensor can be formed directly on the completed IC subsirates. It will be demonstrated that the introduction of polymer layers grealy improves the compatibility of the fabrication process.

\section{Se.isor design}

The structure of the pressure sensor. shown in Fig. I. has been derived from previous developments in the tield of silicon microphones $|9,10|$. The sensor basically consists of 


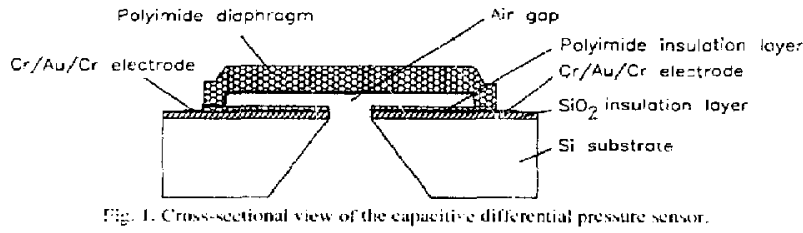

a polyinide diaphragm under which a metal electrode is flaced. On the silicon substratt. a counter electrode is deposiled. and a second polyimide layer is used to provide electricat insulation between the two electrodes. The air gap in the deviee in creat $L$ ol by means of as sacriticial-layer technic|ue in which an aluminium layer is daposited and subsequently etched away. The opening to the sacritieial layer on the backside is made by combined etching of the silicon with potatsium hydroxide (KOH) and reactive ion etching (RIE). Since the whole sensor fabricalion process contains only low. tomperature $\left(<300^{\circ} \mathrm{C}\right)$ 1C-compatible steps, the process can be carried out ats a post-provess on a substrate where integrated circuits have already been complesed. By designing the oir gup in the device correctly, the sensor may be used for positive as well as negittive pressure differences.

\section{Theory of uperation}

A capacitive pressure sensor is a transducer that converts the deflection of a structure. ciused by a pressure load. into a change of electrical capacitance. Therefore, the model ot transduction may be split into two separate parts: one part coneerned with the mechanical properties, which detrermines the deflections in the structure. and ore part concerned with the variation of electrical cupacitance due to the deflection.

For the polyimide, which is used for the diaphragm (Fig. 1). the intrinsic tensile stress has been determined to be approximately $40 \mathrm{MPa}$. Since the Young's modulus of the polyimide is relatively low ( $\approx 7 \mathrm{GPa})$ it is assumed that bending may be neglected. If deflections are small compared with the thickness of the diaphragm, and if the diaphragm is under strang influence of intrinsic stress. the deflecion profilc of the square diaphragm can approximated by $|1|$

$w(x, y)=n_{0} \cos \left(\frac{\pi x}{2 a}\right) \cos \left(\frac{\pi v}{2 a}\right)$

where $a$ is half of the side length. $x$ and $y$ are the principal directions on the diaphragm with origin in the centre, and $w_{6}$ is the centre deflection given by

$H_{i,}=0.328+\frac{p t^{2}}{d h_{\mathrm{L}_{2}}}$

in which $\sigma$ is the intrinsic stress, $h_{\mathrm{t}}$ is the thickness of the diaphragm. and $p$ is the applied pressure load on the diaphragm.
The nuglection of the bending. which is required to atsums the deflection provile (Eq. ( 1$)$ ) introduces an error, but since the diaphratgm is assumed to he in the linear range of deflection. it is possible to introduce a correction factor $K$ in Eq. (2). whith accounts for this erers. Henby. an approximated profile with the correct centre deflection is defined:

$\mathrm{w}_{\mathrm{i}}=K 1 . .328+\frac{p l^{\prime \prime}}{\sigma h_{\mathrm{u}}}$

The matching factor can he detcrmincd by comparing the centre deflection oblained from Ey. 12) with the centre deflection calculated from the combined action of intrinsic stress and bending $\mid\{2 \mid$. For a diaphragm with a side length $700 \mu \mathrm{m}$ and a thickness of $16 \mu \mathrm{m}$. this yields a matching tactor $K=0.57$.

The deflection function given in Eq. (1) may be used to calculate the electrical capacitance of the sensor. Assuming that the gap hetween the diaphragm and the counter electiode is iijled partly with air and partly with the polyimide insulation iayer. the sensor capacitance $C_{\text {vam }}$ can he derived by integrating over the cleflection profile

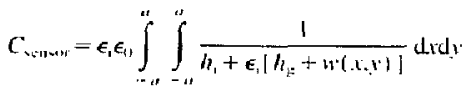

where $\epsilon_{i}$ is the relative permittivily of the polyimide insulation layer. $\epsilon_{10}$ is the putmittivity in vacuum. $f_{1}$ is the thickness of the polyimicte insulation layer and $h_{z}$ is the height of the gap.

For the structure in Fin. I, an air gap $\left(h_{k 2}\right)$ of $5 \mu \mathrm{m}$ and a diaphragm thickness $\left(h_{t_{3}}\right)$ of $16 \mu \mathrm{m}$ were selected. The thickness of the polyimide insulation layer was chosen to be 0.5 $\mu \mathrm{m}$. With the desired presisure range of the sensor being \pm 1 bar. a maximum side length of $82.5 \mu \mathrm{m}$ where $\mu_{11}<5 \mu \mathrm{m}$. can he calculated from $\mathrm{Eq}$. (3). Consequently, a side length of $700 \mu \mathrm{m}$ was chosen, which gives a deflection of $3.6 \mu$.n for a pressure difference of 1 bar. The size of the electrodes wis chosen to be $600 \mu \mathrm{m}$. leaving a ring of $50 \mu \mathrm{m}$ around the diaphragm electrode for verification of the removal of the sacrificial iayer. The initiat capacitance of the sensor with no pressure applied was calculated to be $0.62 \mathrm{pF}$. A finite grid of points on the diaphragn was used to calculate the sensor capacitance at different pressure loads, thereby allowing anal$y$ sis of the siluation where the diaphragm is only partly covcred with the electrode [13]. In Fig. 2, the calculated capacitance of the sensor is shown as a function of the upplied differential pressure. A decrease of $0.14 \mathrm{pF}$ or $22 \%$ is: observed over a pressure range of I bar. 


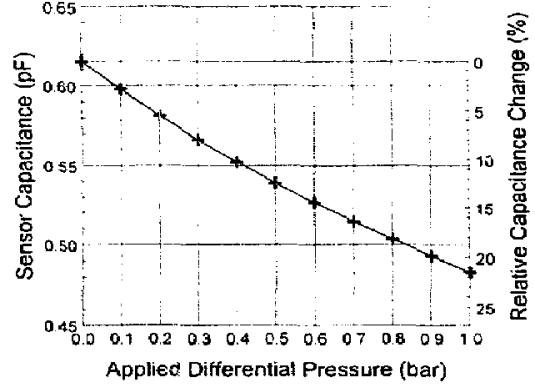

Fig. 2. Simulated semson cupucitance vs, applied diftierential pressure.

\section{Fabrication prociess}

The pressure sensors were made on a $3^{\prime \prime},<100>.400 \mu \mathrm{m}$ thick. $5 \Omega \mathrm{cm}$. p-type silicon substrate (Fig. 3). First. a layer of silicon dioxide with a thickness of $1.5 \mu \mathrm{m}$ was groun thermally at $1150^{\circ} \mathrm{C}$. The silicon dioxide saas patterned on the back, and subsequently used as etch mask for etching of the silicon. The substrate was etched in a $\mathrm{KOH}$ solution
143 u. $\%, 73^{\circ} \mathrm{C}$ ), whereby a reverse pyramid was forned on the sensor backside (Fig. 3A). Thereafter, a chromium/ guld/curomium electrode with a thickness of $4 / 20 / 4 \mathrm{~nm}$ was deposted on the front and patterned using resistive cvapofution and a standard lift-oft process with photoresist. A layer of polyimide was ther deposited over the electrode (Fig. 3B). The polyimide resin used was a $4: 1$ solution of the HTR 3-200 photosensitive polyimide from OCG Micrnelectrunics Inc, and the solvent NMiP ( $N$-methylpyrolidone). The polyirs de solution was spun on to the substrate with a spin speed of $4000 \mathrm{rpm}$ for $90 \mathrm{~s}$. yielding a tinal layer thickness of the polyimide of $=0.5 \mu \mathrm{m}$. To improve tha adhesion of the polyimide on the silicon oxide surfaces. a $\%$ APS promoter (aminopropyltriethoxysilane) was used previous to the application of the polyinide. After spinning. the poly imide was buked at $90^{\circ} \mathrm{C}$ for $25 \mathrm{~min}$ to remove the solvent in the film. The layer was then partly exposed to $350 \mathrm{~mm}$ utraviolet light wih an energy of $15 \mathrm{~mW} \mathrm{~cm}^{-2}$ for $30 \mathrm{~s}$. An intermediate bake at ${ }^{\circ} \mathrm{C}$ for $10 \mathrm{~min}$ was applied, to enhance the pre-polymerization af the exposed areas of the polyimide. The polyimide layer was subsequently developed for $3 \mathrm{~min}$ using the $Q Z$ 3301 Polyimide Developer from Ciba Geigy and rinsed in IPA (isopropyl alcohol), leaving the exposed

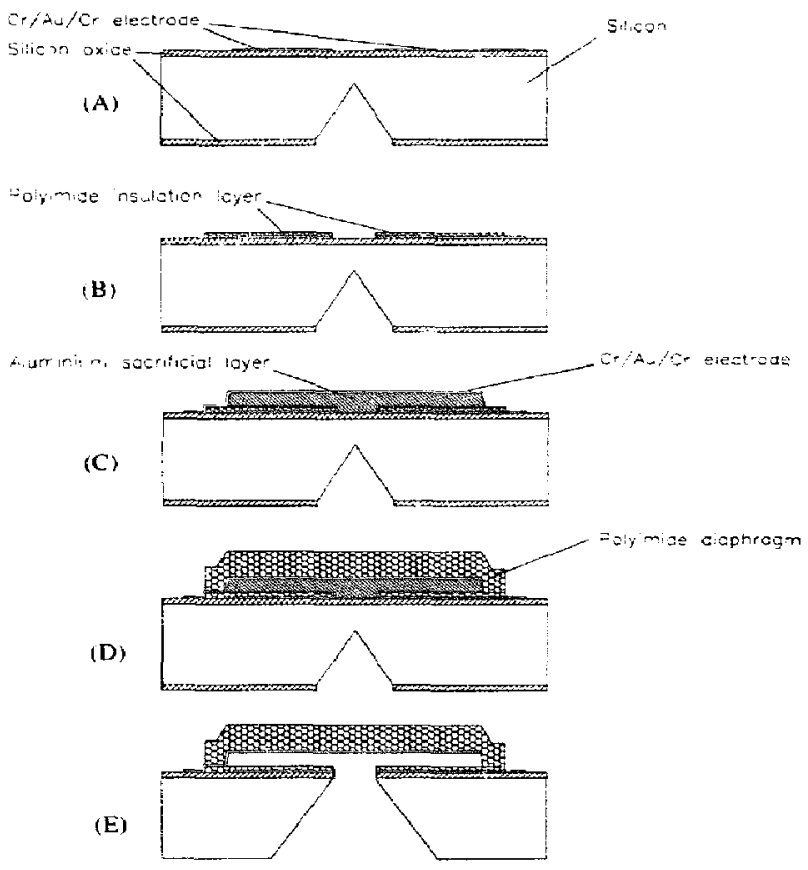

Fig. 3. Senser fabrication precess. 


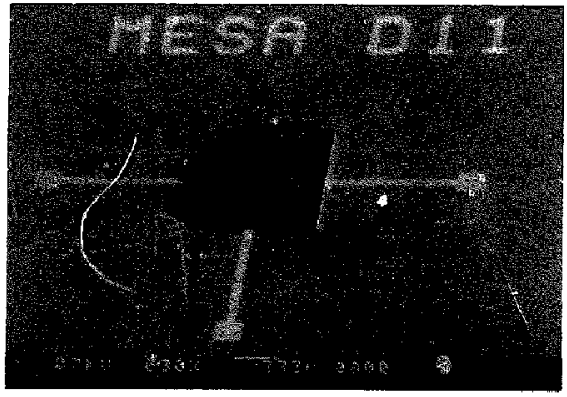

Fig. 4. SEM photograph of a completed sensur.

parts of the layer. Lastly, the layer was cured in an $\mathrm{N}$. at mosphere at $300^{\circ} \mathrm{C}$ for $\mathbf{l} \mathrm{h}$.

An aluminium sacriticial layer was then deposited and patterned (Fig. 3C) using electron-beam evaporation and a standiard aluminiam etch solution. conlaining phosphoric acid, nitric acid and acetic acid. The thickness of the sitcriticial layer was $5 \mu \mathrm{m}$. Subsequently, a chromiam/gold/chromium electrode layer with a thickness of $10 / 3110 / 10 \mathrm{~nm}$ was deposited and patterned with lift-off. This sa idwich layer proves it good eompromise between the low intrinsic stress of gold and the supreme adhesion properties of chromium to polyimide [14]. The polyimide diaphragm was then completed using a process similir to that described above (Fig. 3D). A spin spreed of $1800 \mathrm{rpm}$ for $20 \mathrm{~s}$ with a pure solution of the HTR3-200 polyinide yielded a $15 \mu \mathrm{m}$ thick diaphragm aller curing. Finally, is $50 \mu \mathrm{m} \times 50 \mu \mathrm{m}$ opening to the sacrificial fayer was made on the backside, by etching of the remaining silicon in the reverse pyramid (Fig. 3E). This was done in an Electrotech PF 340 rcactive ion etch reactur using an $\mathrm{SF}_{\mathrm{t}_{1}} /$ $\mathrm{O}_{2}$ plasma with a flow of $30 / 5 \mathrm{sccm}$, a chamber pressure of $75 \mathrm{mtorr}$ and an r.f. power of $75 \mathrm{~W}$. The silicen dioxide left in the top of the pyramid was etched using a $\mathrm{CHF}_{3}$ plasma with a flow of 10 sccm. a chamber pressure of 20 mtorr and an r.l. power of $50 \mathrm{~W}$. A fler etching of the sacrificial layer in the standard atuminium etch solution and rinsing. the structures were dried using a freeze-drying lechnique, in which the liquid in the air gap is chunged to cyclohexane, which is then sublimated by cooling the struciures to $-5^{\circ} \mathrm{C}$. With this method. the problems of sticking of the diaphragra to the substrate were eliminated. Pressure :rensors with the electrode configuration and dimensions described ibove have been completed using this fabricalion , Trocess. In Fig. 4, a frontview SEM photograph of a completed sensor is shown.

\section{Measurements and results}

The sensors were individually mounled on a set-up in which a pressure could he applied to the backside of the sample. The pressure was regulated, using a pressure regu-

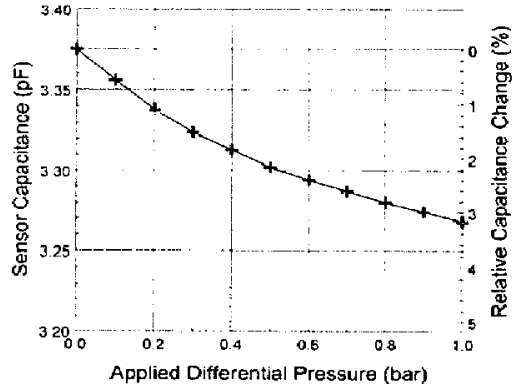

Fig. 5. Measured sensor capicilanee vs. applied differential pressure.

lator ( Wallace and Tiermin Chlorator, type FA-235-6) with manomever. In this set-up. pressures of up to 2.5 bar tan be applied.

First, the sensor was tnounted on a steel support. and connected with bonding wires to a small piece of PCB (printed circuit board). From the PCB, further electrical tonnections to the detection electronics could easily be made. The ahsolute capacilance of the sensor was measured using a HewlettPackard 4194A Impedance/Guin-Phase Anatyzer. In Fig. 5 the measured cupacitance is shown as a funetion of the applied differential pressure. It can be seen that the capaciance decreases for increasing pressure load, meaning that the diaphragm dellects away trom the substrate. Comparing the measurements with the simulations from Fig. 2 , jt is clear that the measured capacitances are much larger. This is believed to be caused by the parasitic capacitance of the clectrical connections. As it san be seen, the relative change $\Delta C / C$ is only $3.2 \%$ over the full range of 1 bar. However. if the effect of the parasitic capacitance $(2.7 \mathrm{pF})$ in parallel with the sennor is subtrieted. the relative change $\Delta C / C$ hecomes $17 \%$ for a pressure range of 1 bar. This is in reasonable agreement with the simulated value of $22 \%$. The remaining differences may be explained by variations in film thicknesse!s and stresses. Especially the built-in stress in the polyimide diaphragm has a strong jnfuence on the sensitivity.

Furthermore, the sensor was tested with a simple detection circuit, potentially suited for integration. The circuit ( Fig. 6) is an istable multivibrator with an LF356 operational amplifier. and five external resistors | 13 | . The cupacitive pressure

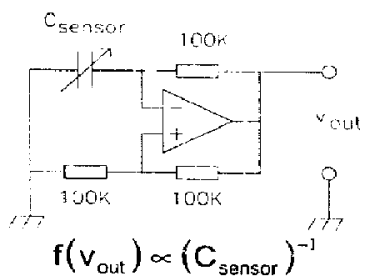

Fig, 6. Detection circuit with irtqueney-modulated sutpul. 


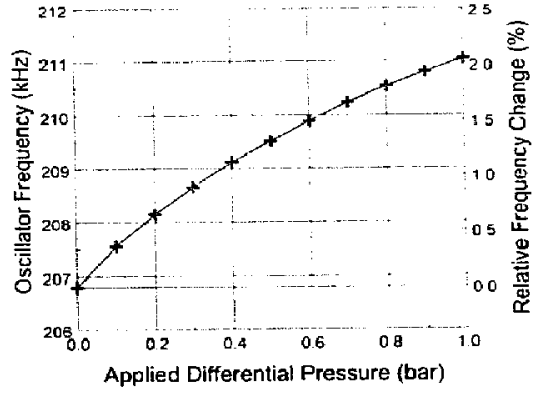

jiy. 7. Osuillator nutput Irexpleticy vs. applisd differential prossure

sensor is the frequency-determining capacitance $C_{\text {cunn }}$ which modutates the frequency of the voltage $r_{\text {inu }}$ on the output of the implitier. Ia the circuit, all resistors werechosen to be $100 \mathrm{k} \Omega$, yielding a base frequency of $207 \mathrm{kH} z$ ii, the oscillator. In Fig. 7, the frequency of the oscillator is shown as a function of the applied differential presstire. The chinge of the frequency was $4 \mathrm{kHz}$ for a pressure range of 1 hile. corresponding to a relative change $\Delta / / f$ of $2 \%$. This sen itivity is again small compared with the theory. but it is stiil in good igreement with the capacitance measurements above. because the parasitic capacitance in tin- detecion circuit wan he larger than the $2.7 \mathrm{pF}$ mentioned above. The jitter of the oscillator. measured with electrical shielding. wis $10 \mathrm{~Hz}$. Since the linearized sensitivity is $+\mathrm{kHz}$ bar' ". this jitter corresponds to a maximum tesolution of $2.5 \mathrm{mbar}$ ( $250 \mathrm{~Pa}$ ). The resolution. however. can be increated considerably by reducing the purasitic capacitances, i.e., by integration of the signal delection circuit.

\section{Conclusions and disctis:ion}

A now capacitive differential pressure sensor has been developed, fabricated and tested. The fabrication of the single-substrate sensor is based on the usc of a polymer ( polyimide) for the pressure-sensing diaphragm. The introduction of this new material in inechanical sensors has greatly improved the IC-compatibility of the entire sensor fabrication process. Consequently, the sensor can be made directly on substrates already containing integrated circuits. and no altention has to be paid to the exact nature of the complex IC process.

The performance of the pressure sensor has been shown to be in good agreement with the theory, and from the measurements it is clear that the presence of parasitics hampers the sensitivity of the sensor. This can be greatly reduced by integrating the delection circuit with the sensor. and it is expected that the sensitivity of the sensor thereby will be close to the theoretical values.
The introduction of a polymer as pressurz-sensing diaphragm might also bring problems, especially regarding ereep and relixation. It is well known that polymers possess viscoelastic properties. and that some relaxation will ecctr. However. : ince polyimide is one of the polymers with the highest glalsi transition temperature $\left(=400^{\circ} \mathrm{C}\right)$, these effects are expected to be very slow. Funhemore, the stress generalcd trom th: pressure load is very small ( $<0.5 \mathrm{MPa}$ ) compared to the suilt-in stress in the film. Accordingly, no drift relating to the sensor has been detected tor a pressure load of I bar over a period of one day. The problem of reiaxation of the built-in siress in the polyimide tilm nay be dealt with by appiying an environmental bum-in period simular to that used in the IC technology. The sensitivity to temperature and humidity of the sensor is also an important issue. First, the thermal stability is affected by the mismatch of the coefficients of thermal expansion ( $\mathrm{CTE}$ ), which is $=50 \mathrm{ppm} \mathrm{K} \mathrm{K}^{-1}$ for polyimides and $\approx 3 \mathrm{ppm} \mathrm{K}^{-1}$ for silicon. This will cisse a reduction of the built-in stress in the diaphragm, and nence in increase in sensitivity for increasing temperatures. Recent developments in polymer science. however, have demonstrated the possibility of synthesizing polyimides with thermat properties closely matched to silicon $[15,16]$. Therefore. in the future it will be possible to realize structures having very litule sensitivity to temperature. Regarding humidity, it is well known that polyimide adsorbs water, leading mosit prominently to a change of the dielectric constant by as much is $35 \%$ over the full humidity range $[14]$. Considering, however. the structure in Fig. 1 , only the thin polyimide insulotion layer is electrically involved in the sensor. Since this layer is 10 times thinner than the air gap, and the dielectric constant is at least three times larger. the change of the sensor capacitince will be small. A calculation of the structure with the dimensions given in this paper shows tal a change of less than $1 \%$ of the sensor capacitance over the full range of humidicy will be caused by the polyimide liyer.

\section{Acknowledgen ents}

The authors are indebted to Johan Bomer for assisting with the processing of the simples. Bert Otter for providing the SEM photographs and the Dutch Technical Foundation ( STW, for tinancial suppon.

\section{References}

11) C.S Santer. J.W. Knutti anü 3.D. Meindl, A monolithic capacitive pressure sensur with pulse-period utput, IEEE Trams. Electrom Divice's, ED-27 (1980) 927-930.

121 W.H. Ko, M.H. Baw and Y.D. Hung. A high-iensitivily intyrutedcircuit capacitive pressure transducer, IHEE Trow. Electron Dforces. ED. $24(1982) 48-56$.

13) A. Hannetorg. T.E. Hansen. P.A. Ohlekers. E. Curlson. B. Duhl and 0. Holwech. An integrated capacitive pressure sensor with frequencymodulated output. Senwors ant Ar whators, 9 (1986) .145-351. 


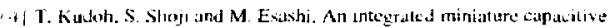

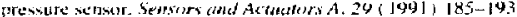

I5: T. Nagata. H. Turabe. S Kuwahatra. S. Sakuraj, O. Tahata, S. Surgyama and ML. Fsushi. Dightal compensaled capacitive pressure se asor wing

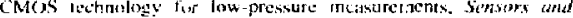
Arthater. A. 3f (1942) 17.3-177.

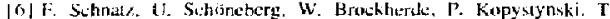
Mellliorn. E. Obernktier had H. Bendel. Sman CMOS cupacitive peesure Iransducer with of -chip calibration capabifity. Sinwers amal di martars A. $3+11909) 77-8.3$.

17) J.T. Kung and H.S. Les. An integrated dir-gap-capucitor pressure

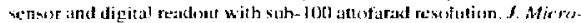

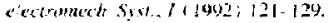

|S| H. Didlaices, M. Kilndlets, Y. Manoli, W. Mokwa and E. Spiegul. Surfiect micromalhinat pressure sensors with integrated radOS

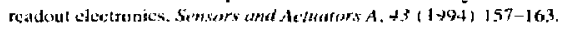

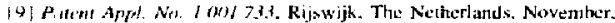
lings.

(10) M. Peder:en. R. Scheltin, W. Olshuin and P. Bergueld. Electro-

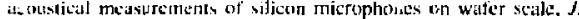

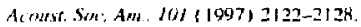

111 I S.P. Timoshenko and S. Woinowaky-Kricger. Theson of Plates arld Siterls. MeGraw-Hil]. Naw York. 2nd edn.. 1059. p 92.

III M. Pederson. W. Olthuis atut $P$. Bergveld. Ot the simulation of subminiature condenter microphnnes using tinite differences, Prat

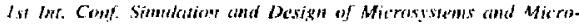

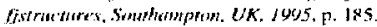

|13] M.G.H. Meijerink. Develupment of at KC-compatible enratitive pressure segsor, Master's The'sis. University of Twenle (1956).

: 14] R.J. Jejsen. J.P. Cummings and H. Vora, Copper/polyinide material system for high pertorthance packuging. HeEE Trum. Compesments

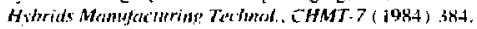

[15] O. Rohde, P. Smolka. P.A. Falcigna and J. Plitiler. Novel autn phutowensilive polyingides with lidilored properticu, Polymer Fing. Srit. .12 (1992) $1623-1629$

$\{1$ G| A.E. Nater, K. Imai. J. Ciaig. C.N. Lazaridis, D.O. Muray IIl, M.T. Pottiger. \& A. Dumbetik and W.J. Litutenberger. Synthesis and chatuclerizalion ol' a jow stress pholusensitive polyimide. Po/romer

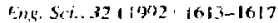

\section{Biographios}

Michael Pedersen was born in Holbak. Denmark, on November 29, 1969. He received the M.Sc, degree in electrical engineering from the Technical University of Denmark in 1993. Currently he is working on a Ph.D. project in the Biosensor Technology Group of the MESA Institute. at the University of Twente. His research is conecrned with thic development of fully integrated silicon condenser microphones

Marn G.H. Meijerink was born in Deventer. The Netherlands, on September 8.1972 . He received the M.Sc degree in electrical engineering from like University of Twente. The Netherlands in 1996. Currently he is working on a Ph.D. project in the Sensors. Actuators a nd Microsystems Laboratory of the Institute of Microlechnology at the University of Neuchätel, Switzeriand.

Wouter Othtuis was born in Apeldoorn. The Netherlinds, on October 23, 1960. He received the M.Sc. degree in electrical engineering from the Univer sicy of Twente. The Netherlands. in 1986. and the Ph.D. degree fron the ! inmedical Engineering Division of the faculty of Electric Engineering. University of Twente, in 1990. Curremt! he is working as an assistant professor in the Bios.:. or Technology Group of the MESA Institute, al the University of 'T'wente.

fie' Berge' on January 26,1940 . He received the $M . S c$. degree in elec'rical engineering from the University of Eindhoven. The Netherlands, in 1965 and the Ph.D. degree from the University of Twente. The Netherlands, in 1973. The subject of his dissiertation was the development of ISFETs and related devices, the actual invention of the ISFET, since then also investigated by many international research groups of Universitics as well as industry. Since 1965 he has been a member of the Biomedical Engincering Division of the Faculty of Electrical Engineering (University of Twente) and was in 1984 appointed as full profeswor in biosensor technology. He is one of the project leaders in the MESA Reseirch Institute. His reseitrch subjects still concern the further development of ISFET technology as well as physical sensors for hiomedical and environmental applications, resulting up to now in more than 200 papers. 